\title{
User perspectives on issues that influence the quality of daily life of ventilator-assisted individuals with neuromuscular disorders
}

\author{
Dina Brooks $\mathrm{PhD}^{1,2}$, Audrey King $M A^{1}$, Mark Tonack $M A^{3}$, Helen Simson $M A^{1,2}$, Maria Gould $M A^{1,2}$, \\ Roger Goldstein MB ChB FCCP 2,4
}

\begin{abstract}
D Brooks, A King, M Tonack, H Simson, $M$ Gould, $\mathrm{R}$ Goldstein. User perspectives on issues that influence the quality of daily life of ventilator-assisted individuals with neuromuscular disorders. Can Respir J 2004;11(8):547-554.
\end{abstract}

OBJECTIVES: To identify user perspectives on the issues that impact the quality of the daily lives of ventilator-assisted individuals living in the community.

METHODS: Semistructured interviews were held with 26 Canadian ventilator-assisted individuals (mean age $44 \pm 14$ [SD] years, range 23 to 60 years; mean ventilator experience $18 \pm 13$ years, range three to 53 years) whose disability from neuromuscular conditions necessitated assistance with activities of daily living. Participants described their daily life experiences and perceptions of the factors that limited or enhanced their quality. Interviews were tape-recorded, transcribed and analyzed for emergent codes and themes.

RESULTS: Ventilator users characterized important issues in terms of personal successes and limitations, as well as dependencies on others for daily living. Personal support services, income security, health care and transportation were important positive contributors to their quality of life. Dependency on others was clearly a negative contributor. The ventilator was regarded as a form of assistive technology, similar to a wheelchair. Ventilator users perceived that ventilation was associated with a stigma and negative assumptions about disability, particularly if suctioning was required.

CONCLUSIONS: The majority of participants considered home mechanical ventilation to be a positive benefit for independent living, enhancing their overall health. They were clear as to the issues of importance to them, and formulated recommendations for health care providers and policy makers that could improve the quality of their daily lives. Many of the issues identified in the present report are faced by the growing community of ventilator users.

Key Words: Daily living; Disability; Interview; Qualitative; Quality of life; Ventilator users
Les perspectives des utilisateurs sur les enjeux qui influent sur la qualité de vie quotidienne de personnes atteintes de troubles neuromusculaires sous ventilation

\begin{abstract}
OBJECTIFS : Connaitre les perspectives des utilisateurs sur les enjeux qui nuisent à la qualité de vie quotidienne des personnes sous ventilation qui vivent dans la collectivité.

MÉTHODOLOGIE : Des entrevues semi-structurées ont été organisées

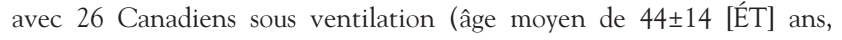
fourchette de 23 à 60 ans, expérience moyenne sous ventilation : $18 \pm 13$ ans, fourchette de trois à 53 ans) dont l'invalidité causée par des troubles neuromusculaires exigeait une ventilation dans les activités de la vie quotidienne. Les participants ont décrit leurs expériences de vie quotidienne et leurs perceptions des facteurs qui limitaient ou amélioraient leur qualité de vie. Les entrevues ont été enregistrées, transcrites et analysées afin de découvrir les codes et les thèmes émergents.

RÉSULTATS : Les participants sous ventilation caractérisent les enjeux importants sous forme de réussites et de limites personnelles, de même que de dépendance envers d'autres pour la vie quotidienne. Des services d'aide personnelle, la sécurité du revenu, les soins de santé et les transports étaient des facteurs contributifs positifs d'importance à leur qualité de vie. La dépendance à d'autres était clairement un facteur négatif. La ventilation était considérée comme une forme de technologie d'aide, similaire à un fauteuil roulant. Selon les participants sous ventilation, la ventilation s'associait à un stigmate et à des hypothèses négatives au sujet des invalidités, surtout si elle exigeait une aspiration.

CONCLUSIONS : La majorité des participants considèrent la ventilation mécanique à domicile un bénéfice pour une vie indépendante, qui augmente leur santé globale. Ils connaissaient clairement les enjeux importants pour eux et ont formulé des recommandations à l'intention des dispensateurs de soins et des décideurs, lesquelles pourraient amélio rer leur qualité de vie quotidienne. La collectivité croissante des personnes sous ventilation affronte bon nombre des enjeux précisés dans le présent rapport.
\end{abstract}

I ong-term mechanical ventilation was popularized during the Lpolio epidemics of the late 1930s when negative pressure ventilation with an 'iron lung' was a lifesaving intervention for those with respiratory muscle paralysis (1). In subsequent years, long-term ventilation became a reality for other individuals with high cervical spinal cord injury, neuromuscular disease or thoracic restriction. Interest in home mechanical ventilation
(HMV) has been driven both by ventilator users and health care professionals in an attempt to facilitate a more natural community-based lifestyle rather than institutionalization. This interest has been fueled by advances in ventilator technology, the availability of home support services and the need to reduce health care resources allocated for the care of ventilated-assisted individuals (VAI) who are clinically stable $(2,3)$.

${ }^{1}$ Department of Physical Therapy, University of Toronto; ${ }^{2}$ West Park Healthcare Centre; ${ }^{3}$ Toronto Rehabilitation Institute; ${ }^{4}$ Department of Medicine, Faculty of Medicine, University of Toronto, Toronto, Ontario

Correspondence: Dr Dina Brooks, Department of Physical Therapy, Room 848, 500 University Avenue, Toronto, Ontario M5G 1 V7.

Telephone 416-978-1739, fax 416-946-8562, e-mail dina.brooks@utoronto.ca 


\section{TABLE 1}

\section{Questions used in the semistructured interview}

1. Please tell me about your life at present in terms of your day-to-day activities including things like work and recreation, your social life, your ability to get out and about.

2. What are you most satisfied with in your life at present?

3. What are you least satisfied with in your life at present?

4. What factors do you think have the most impact on your satisfaction with your life?

5. What factors do you think have the most impact on your dissatisfaction with your life?

6. How do you deal with these factors?

7. What do you think is needed to make it easier for you to get what you want in your day-to-day life?

8. Have things changed for you over time as you have adjusted to living with mechanical ventilation?

9. What do you think has contributed the most to your adjustment to living with a disability?

10. What do you think has contributed the most to your adjustment to using mechanical ventilation?

11. What do you think affects your day-to-day life the most? Having a disability or having to use mechanical ventilation? Is there a difference?

12. What advice would you offer to people who are new to living with mechanical ventilation?

13. What advice would you offer to medical practitioners who work or will work with people who use mechanical ventilation?

14. Is there anything else you think would be useful for us to know about quality of life for people using mechanical ventilation?
Although it is important for those who fund, deliver or receive health care to have an understanding of the issues that impact the daily lives of ventilator users, information in this area is limited. Some reports $(4,5)$ have included measures of health-related quality of life to reflect health status, but these health status instruments were designed and validated among patients who do not actually require ventilation (6-8). Although such instruments do provide useful information on health status, they fail to consider that ventilator users, with their associated disabilities, have unique perspectives on nonhealth-related issues that play an important role in their everyday lives.

There is still a widespread public perception that life for a ventilator user is of poor quality, although reports $(9,10)$ describing the demographics and perspectives of ventilator users have concluded that they adapted well to ongoing HMV, recognized its positive impact and would choose ventilation again if the opportunity arose. The aim of the present study was to extend the current information regarding the perspectives of ventilator users on issues that impact their daily lives. We selected participants with neuromuscular disease rather than patients with primarily obstructive or restrictive disease, because they were more likely to be clinically stable, have longterm experience with HMV and have progressed to a level of disability that would impact on their daily lives. The results are presented as a series of recurrent themes and recommendations voiced by the ventilator users themselves.

\section{METHODS}

Approach

The study design was based on grounded theory, in which an inductive process of reasoning is used to build knowledge (from the ground up) from the day-to-day experiences of individuals and groups (11-15). This approach enabled interpretations to follow the real-world circumstances experienced by study participants. In grounded theory, social reality is related to the meaning individuals attribute to objects (symbols) in their social world rather than on their inherent meanings (13).

A multi-stakeholder team, reflecting the perspectives of health care professionals and ventilator users, developed the semistructured interviews and participated in the data analysis. Ethics approval was obtained from the University of Toronto (Toronto, Ontario) and West Park Healthcare Centre (Toronto).

\section{Subject recruitment}

Inclusion criteria for enrollment were that the participants were 21 to 75 years of age, clinically stable for at least three months, with a diagnosis of neuromuscular disease, a minimum of two years of daily ventilatory support for at least $8 \mathrm{~h}$ of $24 \mathrm{~h}$, activity limitations requiring wheelchair use and residing at home or in a nonhospital institution. Patients with primarily thoracic restrictive (ie, idiopathic kyphoscoliosis), obstructive (ie, chronic obstructive pulmonary disease) or parenchymal restrictive (ie, pulmonary fibrosis) conditions were excluded, as were patients whose underlying impairment had not resulted in substantial activity limitation.

Recruitment strategies included advertising in periodicals associated with disability organizations, contacts with medical and service agencies (eg, respiratory home care companies and the Ontario Ventilator Equipment Pool) and from suggestions made by VAIs. Subject recruitment continued until the criterion of 'saturation' was met. Saturation became evident when no new relevant data emerged from interviews $(15,16)$.

\section{Data collection and analysis}

Face-to-face interviews were conducted by two research associates (HS, MG) in the participant's homes, with the exception of three interviews which were conducted in community centres. Both interviewers were healthy women with a background in education and experience in working with disabled individuals.

After retrieving demographic information, the interview consisted of a semistructured interview with open-ended questions and corresponding prompts (Table 1). The queries were designed to encourage participants to reflect, describe and interpret their life experiences associated with receiving ventilatory support. Specific questions were asked regarding introduction and adjustment to mechanical ventilation, facilitators, barriers, satisfactions and dissatisfactions in daily life, requirements to improve daily life and advice for consumers and providers. The interviews required $1.5 \mathrm{~h}$ to $2 \mathrm{~h}$ to complete. They were recorded and transcribed verbatim.

Data collection was in keeping with the method of inductive analysis $(14,15,17)$. Therefore, the study process consisted of a cycle of data collection, review and interpretation, adjustment of the data collection tool to remove ambiguous or poorly worded questions and completion of data retrieval.

Analysis began after the first three interviews. Transcripts were reviewed for themes, concepts and representative quotations to determine how they may relate to the ventilator user's perspectives on quality of life. Transcripts were then coded to determine the recurrent themes. Interviews resumed and the next batch of 
TABLE 2

Participant characteristics

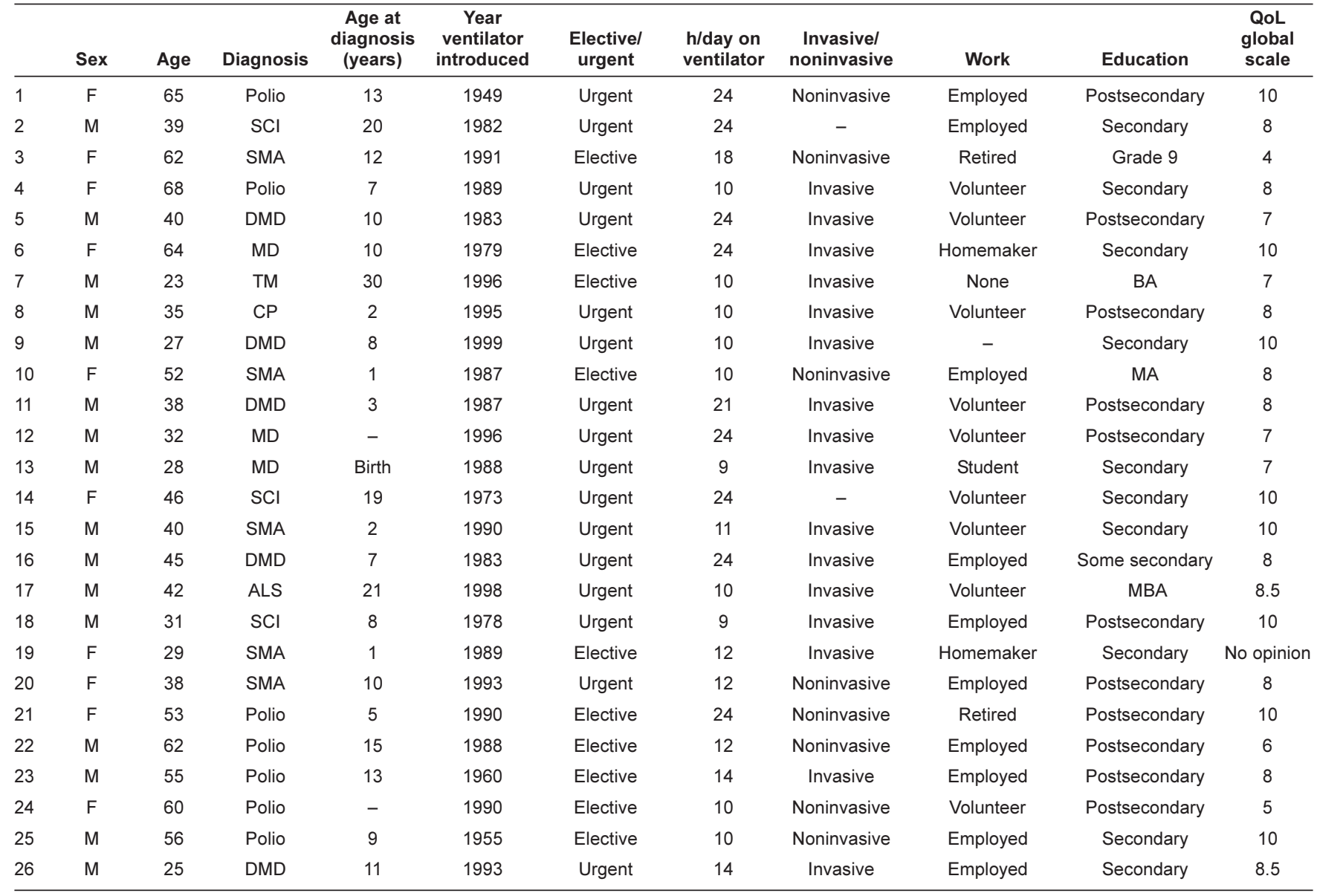

ALS Amyotrophic lateral sclerosis; CP Cerebral palsy; DMD Duchenne muscular dystrophy; F Female; M Male; QoL Quality of life; SCI Spinal cord injury; SMA Spinal muscular atrophy; TM Transverse myelitis

interviews were analyzed similarly, refining the themes and subthemes, throughout the data collection phase. Interview batches were increased to five and then seven subjects. Data collection ended when the team did not identify any new themes (ie, saturation). Following the completion of data analysis, the emerging themes were presented to the participants, in a public forum or by mail, to ensure that the information summarized was consistent with the participants' experiences and perspectives. The participants' review and feedback was incorporated into the final interpretations.

Regular team meetings were undertaken to review transcripts, discuss content and summarize interpretation. One member (HS) coded all transcripts and extracted recurrent themes, but these were verified by at least one other member of the research team. A qualitative research computer software program, NUDIST 4 (QSR International Pty Ltd, USA) was used to facilitate data management.

\section{RESULTS}

\section{Participants}

Thirty consecutive VAIs were approached as soon as their names were provided to the coordinator. Three did not meet inclusion criteria and one refused to participate. Therefore, 26 VAIs participated in the study. Table 2 summarizes the demographic characteristics of the subjects. Sixteen participants were male and 10 were female, with a mean age of
$44 \pm 13$ years (minimum 23 years; maximum 66 years). Only four participants identified specific cultural affiliations (Maltese, Macedonian, Italian and Portuguese). All participants communicated verbally during the interview except for two who used an augmentative or alternative communication device. Three participants had spinal cord trauma and the remainder had neuromuscular conditions. All required ongoing assistance with some aspects of activities of daily living.

Mechanical ventilation was used for an average of $18 \pm 13$ years (minimum three years; maximum 53 years). Positive pressure ventilation was used by all participants except two of the participants with spinal cord injury, who had implanted phrenic nerve pacemakers. Ventilation was invasive (tracheostomy) in 16 participants and noninvasive (face mask, nasal pillow or mouthpiece) in eight participants. Ventilation was required continuously in seven participants, only at night for 16 participants, and at night and part of the day for three participants.

When asked about their daily activities, 10 participants reported being employed or self-employed, eight were volunteers, two had retired, two were homemakers and two were students. Two subjects did not identify any daily 'work' activities. When asked to rate their quality of life using a global nonvalidated scale of 0 to 10 , where 0 reflected very poor and 10 reflected a great quality of life, the mean value was 8.1 (median of 8 ; minimum 4, maximum 10). 
All the participants were from urban centres. They had family physicians as well as respiratory specialists. They were all linked to government-funded home care programs and had regular contact with a respiratory therapist.

All participants provided rich narrative accounts of their introduction and adjustment to ventilation, as well as information about their daily lives and their perception of the factors that limited or enhanced its quality. The results are grouped according to the main themes that arose from the interviews, as well as issue-specific themes that emerged. Representative direct quotations from ventilator users are included.

\section{Adjustment to ventilation}

All participants described an adjustment period that involved practical, physical and psychological adjustments following the initiation of ventilation, or the realization that it was to be permanent. All participants, except one, indicated they had adjusted well to HMV regardless of whether they had been ventilated electively or under urgent circumstances. Individuals who received invasive ventilation without first being offered a trial of noninvasive ventilation expressed regret for what was described as a lost opportunity. Those ventilated electively indicated that their adjustment had been positively influenced by their physician's confidence in the effectiveness of this approach, as well as the experience and opinions of other ventilator users living in the community.

Experiences that made adjustment to ventilation more difficult included the trauma associated with being in an intensive care unit, inability to communicate verbally during ventilation, greater dependence on community-based personal support services, ventilator equipment and the loss of employment (quote 1). Stigma and a sense of being of 'lesser value' to society also increased their initial difficulties in adjusting to home ventilation. Adjustment was more challenging for invasively ventilated individuals because intrusive equipment and frequent suctioning increased their personal care requirements, life style restrictions, stigma and embarrassment (quote 2).

Quote 1: "As I became stronger, I began to think well, what is really different about my care now compared to how it was before the ventilator and then I would reason 'it's something that people could learn, it's not that difficult'".

Quote 2: "I have many more things to do washing equipment, ordering supplies, keeping track of everything. But now I just do it, as part of the everyday routine and it's easier".

However, as their health and energy improved, and daily care routines became more established, new lifestyles emerged that included less focus on the ventilator, which became just another piece of assistive technology, not dissimilar from a wheelchair or a voice synthesizer (quote 3 ).

Quote 3: "It (the ventilator) made me very happy, because it made me comfortable and I wish I'd started long before I did as I might have avoided getting sick so frequently".

Adjustments to HMV were facilitated by opportunities for participant involvement in decision-making such as input into the choice of equipment, trials with different interfaces, personal decisions to limit ventilator time and choosing noninvasive ventilation as an alternative to tracheostomy. Adjustments were also facilitated by the support of family, friends, peers, caregivers, other ventilator users, and by the participant's own positive philosophy and attitudes (quotes 4,5 and 6).
Quote 4: "I have a very supportive husband and son".

Quote 5: "I had great parents obviously, who were determined that I was not going to be institutionalized all my life".

Quote 6: "I never realize it (being ventilated) until something goes wrong, like if I don't have my 100\% support then I realize hey I'm in a wheelchair and you can't do this yourself, right? Otherwise I'm the type of person who never thinks about it, never worries about it and never grieves about it. It's something I have had to do all my life and so I do it. I've always had a positive attitude to life, I've never thought there's anything I couldn't do".

\section{Participating in daily life}

Ventilator users believed that it was important to participate as fully as possible and "contribute" to society. They spent substantial daily time in activities such as employment, education, volunteering, advocacy, homemaking, shopping and travelling. They participated actively in social and recreational pursuits with family, peers, friends and volunteers. Many participants, especially those with limited community mobility, used the Internet extensively for work, recreation and access to the external world. Daily life included personal care routines and activities of daily living, which could be very time-consuming for those requiring tracheostomy care and suctioning. Most participants noted that substantial time was spent scheduling, organizing and coordinating the various support services on which they were dependent (quote 7).

Quote 7: "In the morning I get up, I do my bladder stuff and I do a bowel routine every other day. Then I shower, get dressed and then I get up in the chair. It takes about three hours. I have more things to do. I have to wash the tubes and order supplies such as suction catheters, gauze, etc. I thought, how am I going to do this? It's too many things. But then it gets into your everyday routine and its easier".

\section{Repeating themes that impacted daily living}

Issues relating to ventilator dependence were of much lower consequence (particularly for nocturnal noninvasive ventilation) than issues related to general disability, such as dependence in everyday functional activities of daily and community living. The quality of everyday life was strongly influenced by the satisfaction of successes or the frustration associated with barriers. Health care, supportive housing, income, transportation and self-managed attendant programs emerged as particularly important contributors to daily life.

\section{General satisfaction and success}

Being ventilated was a fundamental source of satisfaction for most VAIs who regarded HMV as a key contributor to their health, energy and ability to participate (quotes 8 and 9).

Quote 8: "My energy was back, I was renewed, I felt wonderful. It was noisy because the air had to escape. It went kshhhhh every breath, but that didn't bother me because I was so glad to have this wonderful thing that was helping me breathe".

Quote 9: "I discovered it just gave me so much more energy to work throughout the day. I figured what the heck, you know, why struggle when I don't have to".

Other sources of life satisfaction included employment, education, advocacy, successful health management and supportive 
relationships with family, friends and volunteers. Many ventilator users described their own positive attitudes and personalities as a source of satisfaction and a facilitator of problem-solving on a daily basis (quote 10).

Quote 10: "I'm a very positive person. I figure that there's no barrier that you can't get over if you try, so I really don't have any difficulties or barriers that I can't overcome. I'm very lucky with my life, extremely lucky to have everything I've had".

\section{Barriers and frustrations}

The barriers and frustrations that respondents identified as impediments to daily living included suctioning, increased care requirements, increased personal attendant requirements and public embarrassment. One of the challenges frequently voiced related to the additional attendant care requirements and provincial health care practitioner legislation that regulated invasive care procedures, thus, restricting those who required frequent suctioning (quote 11).

Quote 11: "Suctioning was a problem at first. We tried different machines. Government was annoying, not enough catheters to allow suctioning every 15 to 20 minutes. Poor quality suctioning machine frequently broke down and there was nowhere to go but the nearest hospital".

Other frustrations related to the lack of control over the requirements of government and service bureaucracies. The energy spent organizing, scheduling and coordinating multiple inter-related health care and social services was another factor which limited quality of life (quotes 12 and 13).

Quote 12: "I could really use a business manager or some kind of general assistant as I don't get around to doing my invoicing. There's are many things of a similar nature that don't get done very well because I'm trying to be my own administrator".

Quote 13: "I am becoming weary of the continuing hassle of dealing with government and health-related organizations. It can take forever to find the right person before something is approved or ordered. I also find it frustrating trying to find the various services (educational, financial, health, etc) that I need to access to meet my unusual needs".

Participants commented on the social stigma and negative assumptions about persons with disabilities, which they perceived as increased with the visible use of HMV in public. Some wheelchair users, who had already accommodated to the challenges of travel, outdoor mobility and building accessibility, found that these challenges had increased, sometimes prohibitively, as wheelchair dimensions and weight were augmented by the addition of a ventilator plus accompanying equipment and supplies (quotes 14, 15 and 16).

Quote 14: "It was a long time before I would go out of the street with a ventilator on my chair, or use it in public".

Quote 15: "I would love to have the nerve to take it (the ventilator) to the theatre for a four-hour performance instead of ducking out during the intermission and going to the car for a 15-minute air break and then going back in".

Quote 16: "I still get embarrassed once in a while if there's a hose loose or something and it starts alarming in a movie theater or in the middle of the church sermon so that everybody turns around".

\section{Health care providers}

Health care providers who recognized and incorporated the knowledge and experience of ventilator users, supported choice, provided education and advocated for their patients, were highly valued. Such individuals were seen as making essential contributions to the positive quality of life of VAIs. In contrast, practitioners who lacked the required specialized knowledge, did not understand or integrate overall care, were unsupportive, inaccessible, made erroneous assumptions or provided inappropriate care, caused frustrations and created barriers. They were seen as detrimental to the quality of life of VAIs.

\section{Transportation}

VAIs who could access the general public transit systems or owned their own vehicles identified transportation as an important contributor to their quality of life. In contrast, those who depended solely on specialized public systems for the disabled perceived its policies and restrictions as impediments to daily life. These included advanced booking requirements, inflexible service times and lengthy, circuitous routes (quote 17).

Quote 17: "You have to wait an hour; you have to be ready an hour ahead. When they pick you up you have to be willing to ride for at least an hour or more to get to your destination. And then you need another hour to wait to return. If you're not right there when they arrive, they won't pick you up. Sometimes they don't show up anyway, then you have to phone them to find out where they are. Scheduling has been a real problem".

\section{Income}

Those who were dependent on public income security programs cited restrictive policies, such as no additional income, as a barrier to quality of life. Insufficient income and complex bureaucratic requirements caused VAIs to live with constant anxiety and insecurity. In contrast, participants whose income came from employment expressed satisfaction with the increased choice, freedom and opportunity made possible by their financial independence.

\section{Self-managed attendant programs}

Several participants directly received public grant monies that were specifically designated for the hiring, training, administering and managing of their own attendant care programs. These participants (who also must accept the legal employer responsibilities associated with this program) noted the dramatic enhancement to their quality of life that had occurred as a result of the greater choice, control and flexibility which was now possible (quote 18).

Quote 18: "I've just basically started on this self-management attendant thing and I think it's really great, being able to control what you need - that has changed my life a lot".

\section{Housing}

Supportive housing and $24 \mathrm{~h}$ on-call support services in rentgeared-to-income apartments provided a valued community alternative to institutionalization. However, even within such settings (as well as for those receiving agency-provided home care), limitations in quality of life were attributed to insufficient staff, prohibited functions (ie, no catheterization, suctioning or medication assistance), lack of choice, incompatibility and 
TABLE 3

Recommendations from ventilator-assisted individuals (VAls)

Greater consumer education and involvement in the approach to ventilation
and choice of equipment, including information on health outcomes,
implications for lifestyle changes and opportunities for networking with
experienced ventilator users.
Direct involvement with manufacturers in the design of smaller, quieter,
more efficient equipment.
Improved education of health care providers regarding home mechanical
ventilation, including access to health care professionals who can
coordinate the required support for VAls within the context of their overall
disabilities.
Enhanced opportunities for VAls to be supported in their own communities,
including self-managed attendant programs, provincial assistive device
programs and increased staff resources.
Support for family caregivers, many of whom are aging, including planning
for future resource availability when family members are no longer able to
provide assistance.
Continuation of programs to support those with disabilities, including
supportive housing, income security, public transportation and allowing
those dependant on such programs to participate in their enhancement
and administration.
Reduced bureaucratic hurdles for service and support access, including
shared administrative requirements among departments.

inflexibility of scheduled routines. Community outings were much more restricted for those requiring suctioning because of the necessity for accompaniment by a qualified caregiver (quote 19).

Quote 19: "I go out shopping once in a while with my family, but I rarely get a chance to go out with my friends because I need suctioning whenever I go out. Although my friends have been trained to do this, they have never actually suctioned me so I don't feel too safe".

\section{Assistive devices}

The provision of assistive devices (eg, ventilator or wheelchair) through publicly funded programs was fundamental to the quality of life of VAIs, although the bureaucracies involved were frustrating. All participants valued opportunities to try various models of equipment. With respect to ventilator equipment, many participants felt limited by its size, bulk and noise, especially at night when sleeping with a partner. However, polio survivors were also aware of the improvement in their quality of life that had became possible through improvements in technology over the past several decades. Many had initiated HMV in an iron lung and were now using small portable positive pressure devices. Limitations on equipment choices through government programs meant that ventilator users could not always access the smaller, quieter ventilators or the most efficient suctioning equipment (quote 20).

Quote 20: “I hate dragging this thing around, but that's a fact of life. Its really hard when you want to travel you have to bring a lot of stuff. You're looking at a ventilator, humidifier, water, suction catheters, cleaning material for your tracheostomy and extras in case something breaks. You go for one or two nights and you're looking at a week of stuff, it's crazy."
What is needed to improve daily living?

VAIs believed that improvements in health care funding, health care professional education and ventilator equipment design would enhance the quality of their lives. Key recommendations for reducing some of the identified barriers included improving public education about life with HMV, integration and access to government programs and improved community accessibility (Table 3). The full text of all quotes and recommendations can be accessed from the Web site www.post-polio.org/ivun. Participants suggested that prospective ventilator users should learn as much as possible about HMV, accept HMV as soon as it is indicated and be aware of the personal responsibilities that HMV involves. Advice to health care providers included supporting the user's decision to proceed to HMV, improving education regarding $\mathrm{HMV}$ and partnering with experienced ventilator users whose expertise could be of great value in establishing optimum care.

\section{DISCUSSION}

The present study was undertaken to identify the perspectives of ventilator users on key elements that impact their daily lives. Despite extensive literature that expresses quality of life in accordance with well established psychometric principles, such measures do not include the perspectives of the individuals in their own words and, therefore, provide an incomplete picture of what individuals perceive as important determinants to their everyday lives. In a critical appraisal of quality of life instruments, Gill and Feinstein (18) noted that the majority $(87 \%)$ of health status measures did not allow for any responses outside the list of selected items. In only three of 75 articles reviewed were patient ratings of the importance of individual problems incorporated into the final score.

Limitations of the present report include the potential for bias related to subject selection using a nonrandomized method of recruitment. There are over 1000 VAIs with neuromuscular disease in Ontario alone. Given that the study participants were recruited through networking and consumer groups, it is possible that those interviewed were more active and fulfilled than the broader HMV population. Their responses may have reflected this end of the spectrum of life experiences. Face-to-face interviews also imply that our subjects were drawn from a geographically confined area and, therefore, were more likely to be able to access community services. The generalizability of the responses may also have been limited by the subjects being heterogeneous in age, sex, mode and duration of ventilator experience, education and employment. However, all of the participants had key attributes in common, such as a neuromuscular diagnosis, ventilation in excess of two years, functional limitations requiring the use of a wheelchair and residence within the community. A distinguishing, positive feature of the study design was the participation of ventilator users who verified the value of the study and evaluated the credibility of the information. Therefore, the common themes and recommendations in the present report are based on the actual needs of ventilator users as opposed to the needs perceived by others.

Despite the many important challenges to daily living, VAIs maintained productive activities and expressed a high regard for the contribution of HMV in making these activities possible. Most rated their quality of life as very high. They were generally proud of their involvement with family and friends, social activities, homemaking, volunteerism, advocacy, 
education and employment. Notwithstanding the bureaucratic frustrations, they recognized the contribution of public support programs, such as supportive housing, personal attendants, assistive technology, transportation, income security and supportive health care in making community living a viable option.

The information provided offers important perspectives that counteract commonly held misperceptions, even by health care professionals, that ventilated individuals live poor quality, unproductive and unsatisfactory lives. Participants in the present study challenged this widespread perception because they were almost universally positive about HMV, and regarded themselves as healthy individuals who were living fulfilling lives. These themes, at least among these 26 subjects, were expressed repeatedly, as more and more participants were interviewed.

With the exception of ventilator specific issues (eg, suctioning, HMV equipment design, interface selection and tracheostomy care), the challenges faced by VAIs were similar to those faced by most individuals with significant physical disabilities who do not require ventilation. These challenges arise from dependence on health services and public support programs over which there is often little choice or influence. The discovery that quality of life issues are more related to general disability than to assisted ventilation was in keeping with observations by Van Kesteren et al (10) who surveyed 38 ventilator users, of whom 26 received invasive ventilation. In most aspects of care, the subjects mentioned problems related to their underlying disability rather than to their ventilator use. However, suctioning was also mentioned as the major issue for patients with a tracheostomy, as well as for their caregivers, who felt tied to them because of the sudden nature of this requirement.

Participants highlighted the importance they placed on the choice of equipment, such as ventilators and interfaces. The issue of choice was seen as highly relevant to a satisfactory adjustment to HMV and to a sense of control over their situation. In a comparison of five bilevel pressure home ventilators among patients with chronic respiratory failure (19), all machines were set to provide the best tolerated inspiratory positive airway pressure and all ventilator inspiratory triggers were set to the lowest default position for each ventilator. Although all machines increased ventilation, with no significant between-machine differences, there was large interpatient variability in airway pressures and wide variations in patient comfort, measured with a visual analogue scale. Given that individuals experienced the sensation of ventilation differently, it is not surprising that VAIs would like to have more influence regarding the choice of their home ventilation equipment. Thus, VAIs should be provided with the opportunity to try different types of ventilators, learn and have input into the decisions made.

Our findings were consistent with other reports $(8,20-23)$ in which life satisfaction questionnaires and health status instruments reflected a positive health-related quality of life, even among very severely impaired individuals. In at least one study of individuals with traumatic tetraplegia (7), the perceived quality of life was higher among severely impaired individuals who received ventilatory support than similarly impaired subjects who were not ventilator dependant. Furthermore, the quality of life of VAIs with tetraplegia was underestimated by health care professionals (7), thus affirming the perception of VAIs that health care professionals consider their lives to be negative and lesser valued. Insights into the issues that impact the daily lives of ventilator users will reduce hardships caused unwittingly by those who may not have had an opportunity to consider their unique perspectives.

The size, noise, bulk and weight of the equipment imposed challenges to mobility and freedom to travel. Based on these research findings, several recommendations from ventilator users were directed to health care professionals, service providers and policy makers (Table 3). These recommendations highlight the importance of partnerships in the support provided for many VAIs who are able to clearly articulate their perspectives on issues that would improve their lives.

Time and experience were important contributors to adjustment to HMV. Although acceptance of family members to HMV varied, most participants indicated that it had not been a major impediment to family life. The support of family, friends and health care professionals was clearly important to the participant's own ability to accept HMV. Our research did not interview the spouses, partners or parents of the ventilator users, but Van Kesteren et al (10), in their survey of ventilator users, did, and found that that almost all partners or parents encountered technical or psychosocial problems, including an increasing burden of care, aging, lack of freedom and financial difficulties. The problems mentioned related more to the patient's increasing disability than to their ventilator use. Our observations were consistent with those of Van Kesteren et al. Participants commented that it was difficult to separate the close association between the impact of their experiences with long-term ventilation from their experiences of severe disability.

\section{CONCLUSIONS}

VAIs with underlying disabilities can provide important personal perceptions of issues that impact their daily lives. These experiences are unique to each individual and are derived from that individual's daily experiences with successes, satisfactions, supports, barriers and frustrations. Issues of choice regarding the services and resources on which they are dependent appear to be greater determinants of their quality of life than the actual impairment or activity limitation (quote 21). The themes and issues delineated in the present report are likely to impact on the growing community of ventilator users, as well as many other individuals with disabilities. Quality of life measures should allow for responses outside the list of selected items.

Quote 21: "I was determined to go on living my life the way I had been and so I didn't really let it affect my lifestyle that much and in the long run it hasn't, other than issues of housing, equipment and attendants, etc, on which I am dependant".

ACKNOWLEDGEMENTS: The authors appreciate the time and energy of the ventilator users who participated, the assistance of the Centre for Independent Living in Toronto, Citizens for Independence in Living and Breathing, and the West Park Healthcare Centre. The authors are grateful to Audrey Runge, Gary MacPherson, Terri Toffen and Barbara Gibson for their help. A full copy of the report can be found at www.post-polio.org/ivun.

FUNDING: Financial support was received from the Thomas Wallace Rogers Memorial Respiratory Research Grant, Gazette International Networking Institute (St Louis, Missouri, USA). 


\section{Brooks et al}

\section{REFERENCES}

1. Muir JF. Home mechanical ventilation. In: Simond AK, Muir JF, Person DJ, eds. Pulmonary Rehabilitation. London: BMJ Publishing Group, 1996.

2. Adams AB, Whitman J, Marcy T. Surveys of long-term ventilatory support in Minnesota: 1986 and 1992. Chest 1993;103:1463-9.

3. Litwin PD, Flegel CM, Richardson BC. An overview of home mechanical ventilation in Canada. Can J Respir Ther 1991;28:67-73.

4. Guyatt GH, Feeny DH, Patrick DL. Measuring health-related quality of life. Ann Intern Med 1993;118:622-9.

5. Lacasse Y, Wong E, Guyatt G, Goldstein RS. Health status measurement instruments in chronic obstructive pulmonary disease. Can Respir J 1997;4:152-64.

6. Bach JR, Campagnolo DI, Hoeman S. Life satisfaction of individuals with Duchenne muscular dystrophy using long-term mechanical ventilatory support. Am J Phys Med Rehabil 1991:70:129-35.

7. Bach JR, Tilton MC. Life satisfaction and well-being measures in ventilator-assisted individuals with traumatic tetraplegia. Arch Phys Med Rehabil 1994;75:626-32.

8. Pehrsson K, Olofson J, Larsson S, Sullivan M. Quality of life of patients treated by home mechanical ventilation due to restrictive ventilatory disorders. Respir Med 1994;88:21-6.

9. Goldstein RS, Psek JA, Gort EH. Home mechanical ventilation. Demographics and users perspectives. Chest 1995;108:1581-6.

10. van Kesteren RG, Velthuis B, van Leyden LW. Psychosocial problems arising from home ventilation. Am J Phys Med Rehabil 2001;80:439-46.

11. Charmaz, K. 'Discovering' chronic illness: Using grounded theory. Soc Sci Med 1990;30:1161-72.

12. Glaser BG, Strauss AL. The Discovery of Grounded Theory: Strategies for Qualitative Research. Chicago: Aldine, 1967.
13. Blumer H. Symbolic Interactionism: Perspective and Method. Englewood Cliffs: Prentice Hall, 1996.

14. Cresswell JW. Qualitative Inquiry and Research Design: Choosing Among Five Traditions. Thousand Oaks: Sage Publications Inc, 1998.

15. Strauss A, Corbin J. Basics of Qualitative Research. London: Sage Publications, 1990.

16. Lincoln YS, Guba EG. Naturalistic Inquiry. Newbury Park: Sage Publications, 1985.

17. Taylor SJ, Bogdan R. Introduction to Qualitative Methods: The Search for Meanings, 2nd edn. New York: John Wiley \& Sons, 1984.

18. Gill TM, Feinstein AR. A critical appraisal of the quality of qualityof-life measurements. JAMA 1994;272:619-26.

19. Vitacca M, Barbano L, D’Anna S, Porta R, Bianchi L, Ambrosino N. Comparison of five bilevel pressure ventilators in patients with chronic ventilatory failure: A physiologic study. Chest 2002;122:2105-14.

20. Markstrom A, Sundell K, Lysdahl M, Anderson G, Schedin U, Klang B. Quality-of life evaluation of patients with neuromuscular and skeletal diseases treated with noninvasive and invasive home mechanical ventilation. Chest 2002;122:1695-700.

21. Gelinas DF, O'Connor P, Miller RG. Quality of life for ventilatordependent ALS patients and their caregivers. J Neurol Sci 1998;160(Suppl 1):S134-6.

22. Lyall RA, Donaldson N, Fleming T, et al. A prospective study of quality of life in ALS patients treated with noninvasive ventilation. Neurology 2001;57:153-6.

23. Bach JR, Campagnolo DI. Psychosocial adjustment of postpoliomyelitis ventilator assisted individuals. Arch Phys Med Rehabil 1992;73:934-9. 


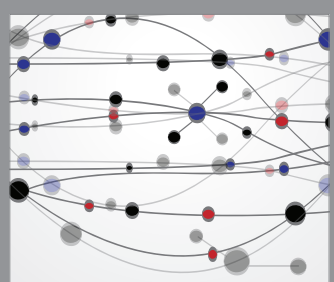

The Scientific World Journal
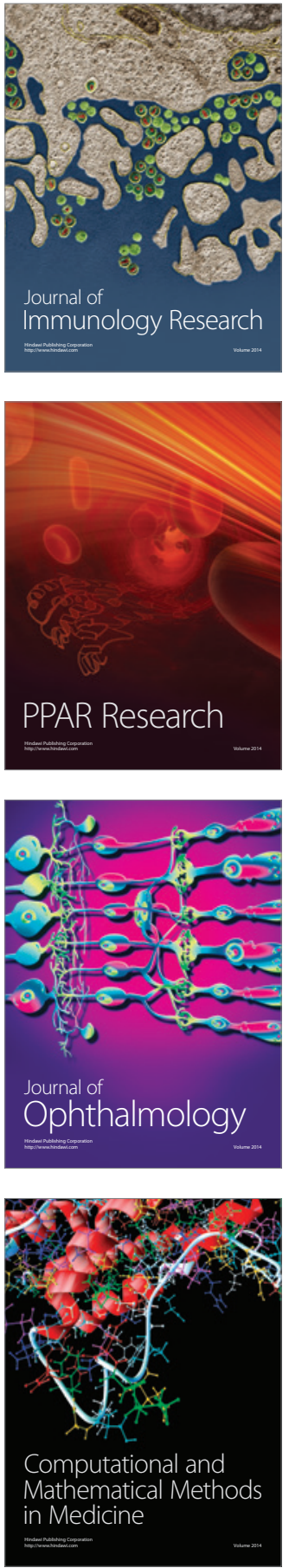

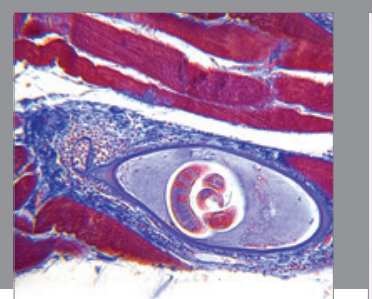

Gastroenterology Research and Practice

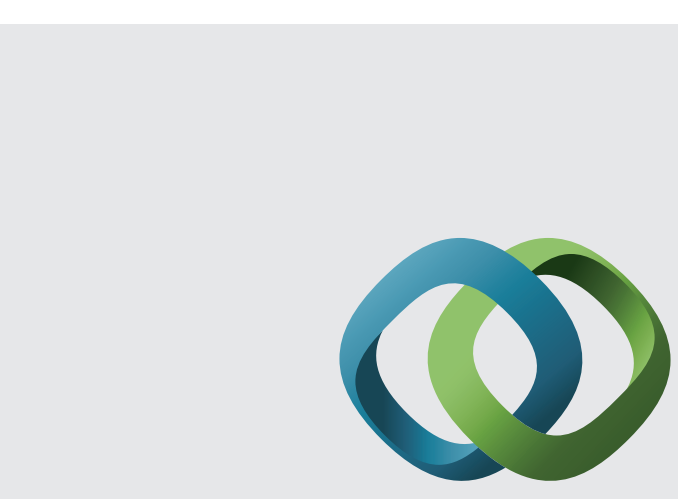

\section{Hindawi}

Submit your manuscripts at

http://www.hindawi.com
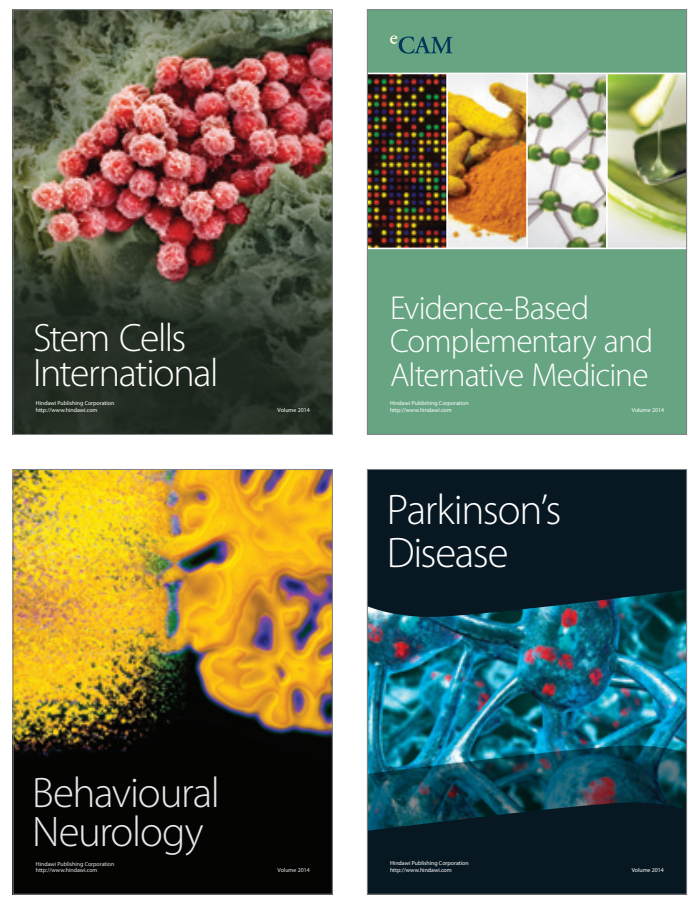
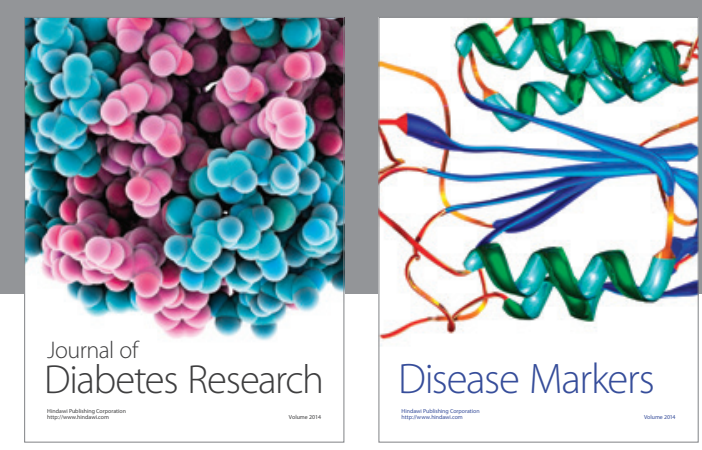

Disease Markers
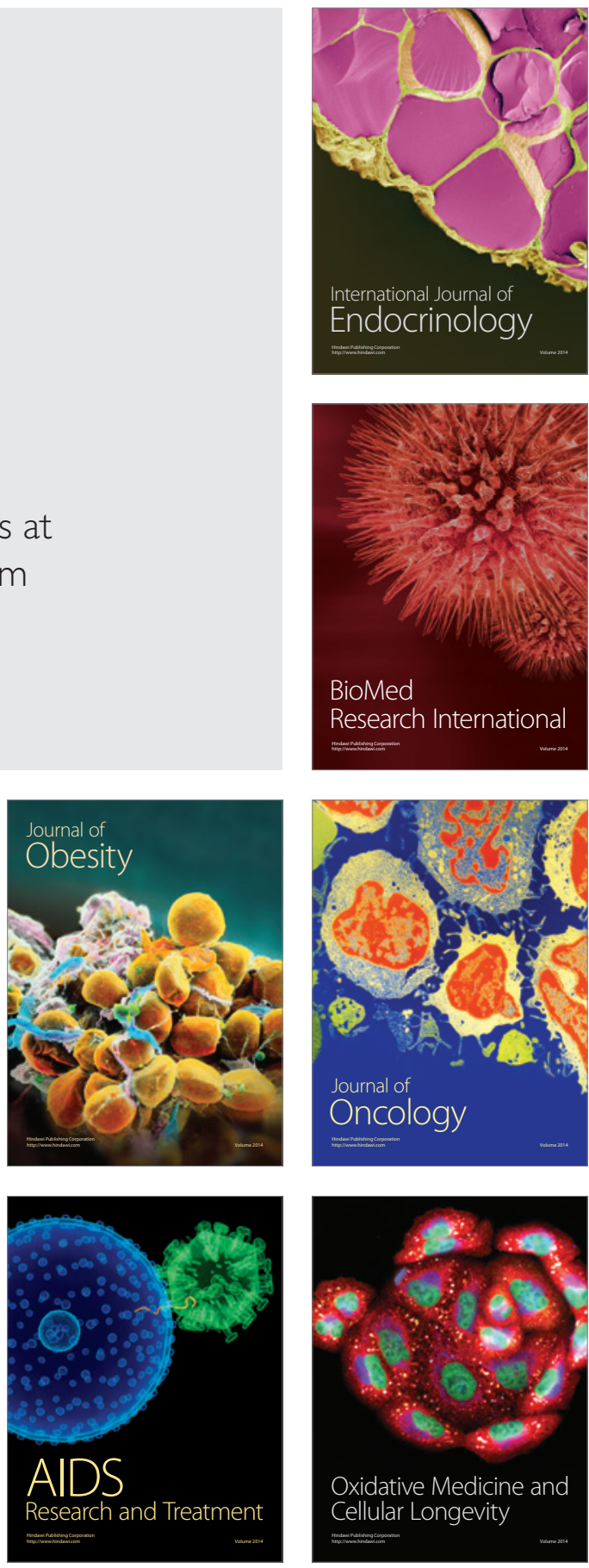